\title{
El asilo diplomático y el principio de no devolución ${ }^{1}$
}

Diplomatic asylum and the principle of non-repayment

\section{Leonel, Caraballo-Maqueira ${ }^{2}$}

\author{
Instituto Superior de Relaciones Internacionales Raúl Roa García, Cuba
}

https://orcid.org/0000-0002-5244-7846

\section{RESUMEN}

El objetivo de este articulo científico es analizar la figura del asilo diplomático en el contexto actual, tomando como referente el caso de Julián Assange, para ello se realizó una revisión documental-bibliográfico transversal, para el análisis cualitativo de la figura del Asilo diplomático y el principio de no devolución. La revisión documental permitió identificar que el asilo es la protección y seguridad que un Estado brinda a una persona extranjera que lo solicita, por estar en peligro su vida y seguridad por razones políticas, económicas, religiosas o científicas. Se concluye que al asilo diplomático se le aplica el principio de no devolución que es norma imperativa en el sistema internacional, reconocido por la Corte Interamericana de Derechos Humanos.

Palabras clave: Asilo diplomático, asilo internacional, derecho internacional, refugio.

\section{ABSTRACT}

The objective of this scientific article is to analyze the figure of the diplomatic asylum in the current context, taking as a reference the case of Julian Assange, for this purpose a cross-sectional documentary-bibliographic review was carried out, for the qualitative analysis of the diplomatic asylum figure and the principle of non-repayment. The documentary review made it possible to identify that asylum is the protection and security that a State provides to a foreign person who requests it, because it is in danger of its life and security for political, economic, religious or scientific reasons. It is concluded that diplomatic asylum is applied to the principle of non-reimstation which is a mandatory rule in the international system, recognized by the Inter-American Court of Human Rights.

Keywords: diplomatic asylum, international law, refuge, territorial asylum.

Recibido: 13 de Febrero 2019 - Aceptado: 26 de Abril 2019

Cómo referenciar este artículo:

Caraballo-Maqueira, L. (2019). El asilo diplomático y el principio de no devolución . Revista Política, Globalidad y Ciudadanía, 97-109. Recuperado de http://revpoliticas.uanl.mx/index.php/RPGyC/article/view/138

\footnotetext{
1 Artículo de revisión derivado del proyecto de investigación: El asilo diplomático y el principio de no devolución

2 Doctor en Ciencias Jurídicas. Profesor Titular del Instituto Superior de Relaciones Internacionales Raúl Roa García. Correo: leonel@isri.minrex.gob.cu

Revista Política, Globalidad y Ciudadanía, Vol. 5 No. 10, Julio - Diciembre 2019, Universidad Autónoma de Nuevo León, Monterrey, México, ISSN 2395-8448. 97-109. http://revpoliticas.uanl.mx/index.php/RPGyC/article/view/138
} 


\section{1.- INTRODUCCIÓN}

La institución del asilo diplomático en América Latina ha jugado un papel fundamental en la protección de la persona perseguida por su ideal político.

El 11 de abril de 2019, el Gobierno ecuatoriano retiro a Julián Assange, el asilo diplomático que le había otorgado en su Embajada en el Reino Unido y lo entrego a las autoridades británicas.

En el Derecho un precedente, una decisión tomada como solución o respuesta a una situación determinada, influye para bien o para mal, en las respuestas que en el futuro se den a situaciones similares. Por ello, lo ocurrido con Julián Assange debe ser analizado por la academia, por cuanto puede tener implicaciones en una institución latinoamericanas como es el derecho de asilo diplomático ¿Es de aplicación al asilo diplomático, el principio de no devolución reconocido como norma imperativa de derecho internacional?

La respuesta a esta interrogante debe partir de la comprensión de la génesis y evolución del asilo diplomático, entender la razón de su surgimiento y analizar a partir de lo dispuesto en los tratados sobre la materia y los pronunciamientos que la Corte Internacional de Justica y la Corte Interamericana de Derechos Humanos el imperio en él, del principio de no devolución.

\section{2.- FUNDAMENTO TEÓRICO}

\section{Asilo}

El Asilo es la protección y seguridad que un Estado brinda a una persona extranjera que lo solicita, por estar en peligro su vida o seguridad personal, por razones políticas, religiosas, científicas o de discriminación. El Asilo, comprende el Asilo Territorial y el Asilo Diplomático.

La institución del Asilo tiene larga data. "En el momento que los Estados modernos se apropiaron de la figura del asilo de una manera secular, se puso fin a una tradición que había durado por más de 1000 años" (Jaramillo, 2012: 82).

En el año 1296 a.m. tuvo lugar la batalla de Kadesh, entre los ejércitos del Faraón Ramsés II y el Rey de los Hititas Hatusil II, que trajo como consecuencia la firma del primer Gran Tratado de Paz y Alianza

El tratado suscrito entre estas dos potencias de la época, acordó la extradición de personas, dispuso que sin importar su rango o condición, el refugiado seria prendido y devuelto al soberano del país del cual huyo, prohibió que a los extraditados se les impusieran castigos, se les infiriera lesiones en su cuerpo, se ejerciera venganza sobre su gente (esposa e hijos), se le destruyera su casa, o se promoviera proceso por delito alguno en su contra (Malpica, 1980: 108-111).

En época tan temprana como en 1296 a.n.e., la vida e integridad de la persona refugiada y 
extraditada eran protegidas y aseguradas.

En Grecia, en sus ciudades estados existía el "asylom (asylum, de asylos: invulnerable), institución asociada a los espacios físicos que eran imponderables, en el cual nadie podía ser violado o vulnerado" (Jaramillo, 2012: 84)

Roma sigue similares derroteros, se protege a la persona en los templos o santuarios hasta que la disputa fuera solucionada o liberada de la esclavitud, se eximían de esta protección por edicto imperial, determinados delitos.

En el Antiguo Testamento, los israelitas reconocen la existencia de ciudades de refugio: "El Señor hablo a Josué y le dijo: Habla con los israelitas y diles que escojan ciudades de refugio" (Jos.201-9) para acoger aquel que mataba a otro sin intenciones y pudiera protegerse de la venganza del pariente más cercano.

"En la civilización azteca, todo esclavo cuya condición se debiera a deudas o delitos, podía recuperar su libertad si alcanzaba a refugiarse en el Tecpán, el palacio real. Solo su amo o los hijos de éste podían oponérsele; ningún otro tenía derecho a impedir la acción de refugio del esclavo bajo la pena de ser considerado el mismo como tal" (Imaz: 1993)

El Corán reconoce el derecho de asilo en la mezquita. "Si uno de los politeístas te pide asilo, ofréceselo hasta que oiga la palabra de Dios y luego hazle llegar a un lugar seguro para él. Eso es porque son un pueblo que no sabe." (9:6)

En el siglo XII el Corpus Iuris Canonice excluía de la protección del asilo los delitos considerados graves. En 1869 el Papa Pio IX declara que tiene el derecho de excomulgar el que viole el derecho de asilo. En 1917 del Código Canónico regula el derecho de asilo hasta 1983 cuando el nuevo Código promulgado por San Juan Pablo II no lo reconoce.

En 1681, el Rey Carlos II brindo refugio en Inglaterra, a los calvinistas franceses que eran perseguidos.

El ascenso económico de la burguesía, frente al autoritarismo monárquico, tuvo como levadura el racionalismo, ese regreso en espirar al humanismo grecolatino. El Homo sapiens pasó de ser objeto, a ser sujeto de la historia, con derecho humanos inalienables e imprescriptibles. La soberanía se consolida en un espacio físico y en una arquitectura jurídica nacional e internacional, que, si bien por veces es vulnerada o manipulada, brinda un margen de estabilidad política en las relaciones internacionales. Las misiones diplomáticas adquieren un carácter de permanente y se impulsa la codificación de lo que hasta ese momento era sostenido fundamentalmente por la costumbre, todo lo cual tiene un necesario impacto en las relaciones internacionales, en que se manifiesta el Asilo.

En toda su evolución, el asilo tuvo como objetivo la protección de la vida del perseguido, durante su permanencia en los lugares sagrados o inviolables, y se brindaban garantías para que 
una vez abandonara el mismo, fuera protegido de la venganza y la persecución.

\section{Asilo Territorial.}

El asilo territorial, tiene su fundamento en la soberanía del Estado (N.U. AG 23/12) y tiene un carácter personalizado. Está dirigido a dar protección a personas individuales cuya vida e integridad está en peligro por razones políticas, a diferencia del refugio que brinda protección a los movimientos masivos de personas que tiene en riesgo su vida, por motivos religiosos, étnicos o raciales, persecución política, conflicto bélico, catástrofe natural, u otra situación que ponga en riesgo su vida.

Al traspasar el perseguido la frontera territorial del Estado asilante, la soberanía de éste se levanta como un escudo protector de su vida y libertad, frente a la acción del Estado perseguidor.

De la Declaración sobre el Asilo Territorial de las Naciones Unidas (N.U. AG 23/12) destacamos dos aspectos:

- Quedan excluidos los que hayan cometido un delito contra la paz, un delito de guerra o un delito contra la humanidad, de los definidos en los instrumentos internacionales elaborados para adoptar disposiciones respecto de tales delitos (Art.1-2).

Sería un contrasentido dar tutela a un verdugo de los derechos humanos.

- La calificación de la causa del asilo corresponde al Estado que lo otorga (Art. 1-3), lo que evita que el Estado de procedencia del asilado lleve a cabo manipulaciones técnicas que descalifiquen el derecho del perseguido a la protección del asilo.

\section{Asilo diplomático.}

Para Vilariño Pintos (2016) el Asilo Diplomático se manifiesta como Derecho Diplomático de Hecho y como Derecho de Asilo Diplomático. En el primer caso, no se genera ninguna obligación ni para el Estado acreditante, ni para la persona asilada que pueda ser exigido al Estado perseguidor, como es la entrega de un salvoconducto que le permita abandonar la sede diplomática y el territorio con seguridad para su persona. Derecho que sí está presente en Derecho de Asilo Diplomático, como lo disponen la Convención de Asilo de La Habana, de 1928 en su artículo 2-3 y el Tratado sobre Asilo y Refugio Político de Montevideo de 1939 en su artículo 6 .

El Derecho de Asilo Diplomático, es una institución fundamentalmente latinoamericana. Para unos estudiosos se fundamenta en la inviolabilidad de los locales diplomáticos, para otros es una expresión de la soberanía territorial que se extrapola como ficción jurídica al espacio de la sede diplomática.

En América Latina, el asilo diplomático tiene su propio desarrollo. 
El 23 de enero de 1889, se firma en Montevideo, por los delegados de la República Oriental del Uruguay y las repúblicas de Argentina, Bolivia, Paragua y Perú, el Tratado de Derecho Penal Internacional, que dispone en su artículo 16, que "El asilo es inviolable para los perseguidos por delitos políticos" y el derecho del jefe de legación de exigir las garantías necesarias para que el refugiado salga del territorio nacional, respetándose la inviolabilidad de la persona (Art. 17). En el Tratado de Montevideo, no se concibe la devolución del asilado y comienza a dibujarse en el imaginario jurídico lo que hoy conocemos como el principio de no devolución.

En 1927, una Comisión de Jurisconsultos reunidos en Rio de Janeiro, preparo y aprobó un Proyecto sobre Asilo que disponía que el asilo concedido a delincuentes políticos en las legaciones, seria respetado (Art. 2), el artículo 7 prescribe que los asilados no podrán ser desembarcados en ningún punto del territorio nacional ni el lugar demasiado próximo a él (Bustamante, 1938)

Como explica Bustamante, la Conferencia Panamericana que tuvo lugar en 1928 en La Habana, incorpora a la Convención de Asilo con un mayor grado de concreción, lo expresado en el Proyecto de Rio de Janeiro. Dispuso en su artículo 2, el asilo de delincuentes políticos en Legaciones, navíos de guerra, campamentos o aeronaves militares como un derecho o humanitaria tolerancia y no establece en su articulado la devolución del asilado al Estado territorial.

De la Convención de Asilo adoptada en la Sexta Conferencia Internacional Americana, que tuvo lugar en La Habana en 1928, destacamos los aspectos siguientes:

1. Dispone que el asilo se concederá en caso de urgencia y por el tiempo estrictamente indispensable para que asilado se ponga de otra manera en seguridad. (Artículo 2- 1), seguridad que tiene implícito su no devolución.

2. Garantiza la transparencia en las relaciones diplomáticas al disponer que se debe poner en conocimiento del Ministro de Relaciones Exteriores o de la autoridad administrativa competente del país donde está la sede diplomática la concesión del asilo. (Art. 2- 2), como paso previo al otorgamiento del salvoconducto.

3. El Agente diplomático del país que, concedido el asilo, puede exigir las garantías para que se respete la inviolabilidad de la persona. El asilado no podrá ser desembarcado ni en el territorio nacional ni en un lugar próximo a él. (Art 2- 3 y 4) lo cual reitera de manera implícita la no devolución.

4. El asilado no puede practicar actos contrarios a la tranquilidad pública, de lo contrario la sede no estaría contribuyendo a fomentar las relaciones de amistad entre ambos países, a la luz de la Convención de Viena sobre Relaciones Diplomáticas. (Art. 2- 5)

La delegación de los Estados Unidos de América, presento reservas a la Convención de La Habana, haciendo contar que no reconocían y no firmaban la llamada doctrina del asilo como parte del Derecho Internacional.

El Tratado sobre Asilo y Refugio Político de Montevideo de 1939 retoma las normas fundamentales de la Convención de La Habana de 1928, y regula como aspecto novedoso, la posibi- 
lidad de dar asilo a un número de personas que excedan la capacidad normal de los lugares de refugio, habilitando otros locales bajo el amparo de su bandera, lo cual debe ser comunicado a las autoridades del país donde está acreditada la sede diplomática (Art.8).

El artículo 8 del Tratado sobre Asilo y Refugio Político de Montevideo de 1939 daba respuesta a futuro, a situaciones como las enfrentadas por varias embajadas durante la Guerra Civil española (1936-1939). En 1937 hubo 7500 asilados reales en locales diplomáticos, lo que llevó al cuerpo diplomático (excepto EE. UU, Reino Unido, URSS, Ecuador, Irlanda y Japón) representado por su Decano, a establecer las coordinaciones con el gobierno español para enfrentar este asilo masivo. (Vilariño Pintos, 2016).

La Convención sobre Asilo Territorial, adoptada en la Décima Conferencia Interamericana realizada en Caracas, el 28 de marzo de 1954, dispone en sus artículos 1 y 2 que, en ejercicio de su soberanía, el Estado tiene el derecho de admitir dentro de su territorio a los perseguidos por sus creencias, opiniones o filiación políticas. Permite la libertad de expresión del pensamiento, de reunión o asociación de los asilados o refugiados, siempre y cuando no inciten al empleo de la fuerza o violencia contra el gobierno de otro Estado (artículos VIII y IX) y dispone que ningún Estado está obligado a entregar a otro Estado o a expulsar de su territorio o extraditar, a personas perseguidas por motivos políticos (Art. III y Art, IV), lo cual está en correspondencia con la Declaración Universal de los Derechos Humanos, proclamados seis años antes, por Resolución 217-A (III) de 10 de diciembre de 1948 de la Asamblea General que en su artículo 14 dispone que "en caso de persecución toda persona tiene derecho a buscar asilo y disfrutar de él cualquier país".

El derecho de asilo ha tenido su reflejo en el constitucionalismo latinoamericano. (ACNUR, s.f.), en la tabla 1, se describen los países en América latina que reconocen el Asilo dentro su marco jurídico.

Cuadro 1. Países que recogen la figura del Asilo.

Artículo 29 de la Constitución Política. (2009)

I. Se reconoce a las extranjeras y los extranjeros el derecho a pedir y recibir asilo o refugio por persecución política o ideológica, de conformidad con las leyes y los tratados internacionales.

\begin{tabular}{l|l} 
Bolivia & II. Toda persona a quien se haya otorgado en Bolivia asilo o
\end{tabular} refugio no será expulsada o entregada a un país donde su vida, integridad, seguridad o libertad peligren. El Estado atenderá de manera positiva, humanitaria y expedita las solicitudes de reunificación familiar que se presenten por padres o hijos asilados o refugiados. 
Brasil

Colombia

Costa Rica

Cuba

Ecuador

El Salvador
Artículo 4 de la Constitución Política (1988):

La República Federativa de Brasil se rige en sus relaciones internacionales por (...) la concesión de asilo político.

Parágrafo único: La República Federativa del Brasil buscará la integración económica, política, social y cultural de los pueblos de América Latina, con vistas a la formación de una comunidad latinoamericana de naciones.

Artículo 36 de la Constitución Política (1991):

Se reconoce el derecho de asilo en los términos previstos en la ley.

Artículo 31 de la Constitución Política (1949):

El territorio de Costa Rica será asilo para todo perseguido por razones políticas. Si por imperativo legal se decretare su expulsión, nunca podrá enviársele al país donde fuere perseguido.

Artículo 17. De la Constitución (2019)

La República de Cuba puede conceder asilo, de conformidad con

la ley, a los perseguidos por sus ideales o luchas por la liberación nacional, por actividades progresistas, por el socialismo y la paz, por los derechos democráticos y sus reivindicaciones, así como a los que luchan contra el imperialismo, el fascismo, el colonialismo, el neocolonialismo y cualquier otra forma de dominación, la discriminación y el racismo.

Artículo 41 de la Constitución (2008):

Se reconocen los derechos de asilo y refugio, de acuerdo con la ley y los instrumentos internacionales de derechos humanos. Las personas que se encuentren en condición de asilo o refugio gozarán de protección especial que garantice el pleno ejercicio de sus derechos. El Estado respetará y garantizará el principio de no devolución, además de la asistencia humanitaria y jurídica de emergencia.

No se aplicará a las personas solicitantes de asilo o refugio sanciones penales por el hecho de su ingreso o de su permanencia en situación de irregularidad.

\section{Artículo 28 de la Constitución Política (1983):}

El Salvador concede asilo al extranjero que quiera residir en su territorio, excepto en los casos previstos por las leyes y el derecho Internacional. No podrá incluirse en los casos de excepción a quien sea perseguido solamente por razones políticas 
Honduras

México

Nicaragua
Artículo 101 de la Constitución (1982):

Honduras reconoce el derecho de asilo en la forma y condiciones que establece la Ley. Cuando procediere de conformidad con la Ley revocar o no otorgar el asilo, en ningún caso se expulsará al perseguido político o al asilado, al territorio del Estado que pueda reclamarlo.

El Estado no autorizará la extradición de reos por delitos políticos y comunes conexos.

Constitución Política de los Estados Unidos Mexicanos (1917 y sus reformas)

Artículo 11. (...)

Toda persona tiene derecho a buscar y recibir asilo. El reconocimiento de la condición de refugiado y el otorgamiento de asilo político, se realizarán de conformidad con los tratados internacionales. La ley regulará sus procedencias y excepciones.

Artículo 5 de la Constitución Política (1987):

Nicaragua fundamenta sus relaciones internacionales en la amistad y solidaridad entre los pueblos y la reciprocidad entre los Estados. Por tanto, se inhibe y proscribe todo tipo de agresión política, militar, económica, cultural y religiosa, y la intervención en los asuntos internos de otros Estados. Reconoce el principio de solución pacífica de las controversias internacionales por los medios que ofrece el derecho internacional, y proscribe el uso de armas nucleares y otros medios de destrucción masiva en conflictos internos e internacionales; asegura el asilo para los perseguidos políticos, y rechaza toda subordinación de un Estado respecto a otro.

Artículo 42 de la Constitución Política:

En Nicaragua se reconoce y garantiza el derecho de refugio y de asilo. El refugio y el asilo amparan únicamente a los perseguidos por luchar en pro de la democracia, la paz, la justicia y los derechos humanos. La ley determinará la condición de asilado o refugiado político, de acuerdo con los convenios internacionales ratificados por Nicaragua. En caso de que se resolviera la expulsión del asilado, nuca podrá enviarse al país donde fuese perseguido 
Paraguay

Perú

Venezuela

República

Dominicana

Fuente: ACNUR, s.f..
Artículo 43 de la Constitución (1992):

El Paraguay reconoce el derecho de asilo territorial y diplomático a toda persona perseguida por motivos o delitos políticos o por delitos comunes conexos, así como por sus opiniones o por sus creencias. Las autoridades deberán otorgar de inmediato la documentación personal y el correspondiente salvo conducto. Ningún asilado político será trasladado compulsivamente al país cuyas autoridades lo persigan.

Artículo 36 de la Constitución (1993):

El Estado reconoce el asilo político. Acepta la calificación del asilado que otorga el gobierno aislante. En caso de expulsión, no se entrega al asilado al país cuyo gobierno lo persigue.

Artículo 69 de la Constitución (1999):

La República Bolivariana de Venezuela reconoce y garantiza el derecho de asilo y refugio. Se prohíbe la extradición de venezolanos y venezolanas.

Artículo 46 de la Constitución Política (2010): Toda persona que se encuentre en territorio nacional tiene derecho a transitar, residir y salir libremente del mismo, de conformidad con las disposiciones legales.

1) Ningún dominicano o dominicana puede ser privado del derecho a ingresar al territorio nacional. Tampoco puede ser expulsado o extrañado del mismo, salvo caso de extradición pronunciado por autoridad judicial competente, conforme la ley y los acuerdos internacionales vigentes sobre la materia;

2) Toda persona tiene derecho a solicitar asilo en el territorio nacional, en caso de persecución por razones políticas. Quienes se encuentren en condiciones de asilo gozarán de la protección que garantice el pleno ejercicio de sus derechos, de conformidad con los acuerdos, normas e instrumentos internacionales suscritos y ratificados por la República Dominicana. No se consideran delitos políticos, el terrorismo, los crímenes contra la humanidad, la corrupción administrativa y los delitos transnacionales.

El Derecho Internacional en su conformación no es ajeno a la política y esta no es ajena a la economía. Hay un flujo y reflujo constate entre ellas, pero la estabilidad y seguridad internacionales necesitan de reglas de conducta, que, asumidas por los Estados de manera soberana, se traducen en tratados y acuerdo que ordenan y regularizan las relaciones internacionales, donde el derecho diplomático con su ancestral voluntad negociadora y arropado en la inviolabilidad de sus locales, asume un papel central en el derecho de asilo.

\section{Principio de no devolución.}

Revista Política, Globalidad y Ciudadanía, Vol. 5 No. 10, Julio - Diciembre 2019, Universidad Autónoma de Nuevo León, Monterrey, México, ISSN 2395-8448. 97-109. http://revpoliticas.uanl.mx/index.php/RPGyC/article/view/138 
En América Latina hubo un hecho que sentó un precedente en cuanto al análisis del asilo diplomático.

El 3 de enero de 1949 el Embajador de Colombia en Perú concedió asilo diplomático a Víctor Raúl Haya de la Torre, dirigente del Partido Alianza Popular Revolucionaria Americana, acusado de instigar la rebelión militar que tuvo lugar en el Perú. El Embajador de Colombia en Perú, solicito un salvoconducto que permitiera a Haya de la Torres abandonar el país. El Gobierno peruano denegó el salvoconducto aduciendo que Haya de la Torre había cometido delitos comunes. Ambas partes pusieron en conocimiento de la Corte Internacional de Justicia la Litis.

Respecto a la posibilidad de retirar la condición de asilado, la Corte Internacional de Justicia en su fallo de 13 de junio de 1951 expreso "conforme a la tradición latinoamericana en materia de asilo, con arreglo a la cual un refugiado no debe ser entregado. (...) Para abandonarla, se habría requerido una disposición convencional expresa; el silencio de la Convención implica que se ha querido dejar la solución de tales circunstancias en decisiones inspiradas por consideraciones de conveniencia o simple oportunidad política." Y reconoce que "la entrega del asilado no es la única forma de poner fin al asilo”.

La Convención de Asilo de La Habana de 1928 como ya hemos señalado, no autoriza la entrega del asilado una vez retirado el asilo diplomático. La Convención sobre asilo territorial de Caracas de 1954 prohíbe la extradición del perseguido político.

El Tratado sobre Asilo y Refugio Político de Montevideo de 1939, en su artículo 5, dispone que mientras dure el asilo "no se permitirá a los asilados practicar actos que alteren la tranquilidad pública o tiendan a participar o influir en actividades políticas. Los agentes diplomáticos o comandantes requerirán a los asilados sus datos personales y la promesa de no tener comunicación con el exterior sin su intervención expresa. La promesa por escrito y firmada, si se negara o infringiera cualquiera de esas condiciones, el agente diplomático o comandante hará cesar inmediatamente el asilo" lo que no significa la entrega del asilado a las autoridades locales, la "entrega no es único modo de poner fin al asilo." (Corte Internacional de Justicia. Caso Haya de la Torres. Fallo de 13 de junio de 1951).

La Opinión Consultiva de la ACNUR sobre aplicación extraterritorial de las obligaciones de no devolución en virtud de la Convención sobre el Estatuto de los Refugiados de 1951 y su Protocolo de 1967, “ofrece un panorama general de las obligaciones de no devolución de los estados con respecto a los refugiados y solicitantes de asilo" (ACNUR, Opinión Consultiva; 1) expresa que la prohibición de devolución ante un peligro de persecución se extiende a su entrega, lo cual está en correspondencia con el Pacto Interamericano de Derechos Civiles y Políticos de 1966, según interpreta el Comité de Derechos Humanos (ACNUR, Opinión Consultiva: 10).

La Opinión Consultiva No.4-3-21/2016 presentada a la Corte Interamericana de Derechos Humanos, por solicitud del Gobierno de Ecuador relativa a "El alcance y fin del derecho de asilo a la luz del derecho internacional de los derechos humanos, del derecho interamericano y del derecho internacional" expresa que se debe tomar en cuenta el enriquecimiento de la figura del

Revista Política, Globalidad y Ciudadanía, Vol. 5 No. 10, Julio - Diciembre 2019, Universidad Autónoma de Nuevo León, Monterrey, México, ISSN 2395-8448. 97-109. http://revpoliticas.uanl.mx/index.php/RPGyC/article/view/138 
asilo en sus diversas modalidades y las interpretaciones que se han hecho del "derecho a buscar y recibir asilo a la luz del artículo 22.7 de la Convención Americana de Derechos Humanos y del artículo XXVII de la Declaración Americana de los Derechos y Deberes del Hombre" (Corte Interamericana de Derechos Humanos; Opinión Consultiva No.4-3-21/2016: 2)

La Comisión de Derecho Internacional, en su Cuarto Informe sobre las normas imperativas de derecho internacional general (ius cogens) prestado por DireTladi, Relator Especial, reconoció que el "principio de no devolución es otro de los principios del derecho internacional cuya candidatura a figurar entre las normas de carácter imperativo cuenta con un amplio apoyo y que su vinculación por la Corte Interamericana de Derechos Humanos a la prohibición de la tortura, lo convierte en un principio absoluto "y adquiere también carácter de norma imperativa de derecho internacional consuetudinario, es decir de ius cogens. (Corte Interamericana de Derechos Humanos; Opinión Consultiva No.4-3-21/2016: 2)

\section{3.- MÉTODO}

\section{Diseño}

El presente artículo científico, presenta un enfoque cualitativo, dado que busca encontrar nuevos datos que ayuden a interpretar el asilo diplomático que la literatura científica se ha encargado de estudiar, para ello se efectuó una investigación cualitativa (Sampieri, 2014). El enfoque se basa en una recolección de datos no estandarizados.

Se revisó la literatura disponible sobre el asilo diplomático, identificando que no existe publicación que lo relacione con el principio de no devolución, lo cual caracteriza el presente artículo como novedoso.

\section{Instrumentos}

Se llevo a cabo una revisión de bibliografía de la figura jurídica del Asilo, y se analizaron artículos de revistas especializadas y disposiciones de organismo internacionales relacionados con el tema, lo que permitió la construcción de nuevos razonamientos.

\section{Procedimiento}

El artículo científico se desarrolló a partir de la búsqueda de material académico que tratara sobre los temas de Asilo diplomático y principio de no devolución, los que fueron objeto de análisis que fundamentan las conclusiones a que se arriban.

\section{4.- CONCLUSIONES}

Latinoamérica ha realizado destacados aportes al derecho internacional y uno de ellos es el Derecho de Asilo Diplomático a los perseguidos políticos. 
En todo el desarrollo del Asilo, tanto en su concreción territorial como diplomática, la tradición y su reflejo normativo, han delineado aspectos esenciales.

Se otorga a perseguidos políticos cuya vida e integridad personal peligra.

La calificación de la conducta es del Estado que otorga el asilo.

Se garantiza al asilado el derecho a no ser expulsado, extraditado o devuelto a cualquier otro Estado en que pueda ser objeto de persecución, como una condición necesaria para garantizar su vida y seguridad personal. Así se dispuso desde la antigüedad, hasta nuestros días, con la Declaración 23/21 (N.U. AG 23/12) de las Naciones Unidas.

El análisis de la relación que existe entre el asilo diplomático y el principio de no devolución, no se agota en este artículo científico, el tema de investigación no se agota en este artículo. La realidad de nuestro Continente exige de la Academia un pensamiento crítico que defienda la institución de asilo, como una garantía del ejercicio de los derechos humanos.

El principio de no devolución, es una garantía para el asilado que ha ejercido su derecho a tener una opinión política o criterio diferentes, a que su vida o seguridad personal peligren, con su devolución al país que lo persigue. Es una obligación para el país que otorga el asilo de no entregarlo a sus captores.

Los romanos cuya sabiduría jurídica llega hasta nuestros días sentenciaron, "Ubie ademest ratio, eadem jurisdis positeio sse debet (Donde hay igual razón, debe haber igual disposición) (Digesto, lib. I, tit. III, leyes 4ta, 5ta, 6ta, 12, 13 y 32). Por lo que "sin importar cuál sea la modalidad del asilo otorgado o bajo qué régimen regional de derechos humanos o de derecho humanitarito ha sido otorgado el derecho de asilo o el estatuto de refugiado, la protección del principio de no devolución es universal." (Corte Interamericana de Derechos Humanos; Opinión Consultiva No.4-3-21/2016: 23)

La entrega de Julián Assange por el gobierno ecuatoriano de Lenin Moreno al gobierno británico, con la certidumbre de su extradición a EE.UU. donde será juzgado y condenado, constituye una violación del principio de no devolución reconocido como norma imperativa de derecho internacional consuetudinario, que no admite excepciones, según criterio de la Asamblea General de Naciones Unidas. (Corte Interamericana de Derechos Humanos; Opinión Consultiva No.4-3-21/2016: 2).

\section{REFERENCIAS}

ACNUR (s.f.). El derecho de asilo figura en la constitución. Recuperado de: https://acnur.org/ fileadmin/Documentos/Proteccion/Buenas_Practicas/9208.pdf

Convención sobre Asilo de La Habana. 1928

Convención Americana de Derechos Humanos. 1969 
Convención sobre el Estatuto de los Refugiados de 1951 y su Protocolo de 1967.

Corte Internacional de Justicia. Caso Haya de Torres. Fallos de 20 de noviembre de 1950 y 13 de junio de 1951.

Corte Interamericana de Derechos Humanos, por solicitud del Gobierno de Ecuador. Opinión Consultiva No.4-3-21/2016.

Declaración Americana de los Derechos y Deberes del Hombre (1948).

Declaración sobre el Asilo Territorial de las Naciones Unidas.N.U. AG 23/12.

Diez de Velazco, M. (1990) Instituciones del Derecho Internacional Público. Madrid. Tecnos. S.A.

Imaz, C. (1993). El asilo diplomático en la política exterior de México. Revista Mexicana de Política Exterior, 40 (41), 53-71. Recuperado de https://revistadigital.sre.gob.mx.

Jaramillo Echavarría, R. (1980) El Concepto religioso de refugiado: los santuarios, la tradición y la fe. Virages, 14 (2), $79-97$.

Malpica de Lamadrid. L. (1981). La Historia comienza en Egipto con un acto de Derecho Internacional. México D.F.: Grijalbo S.A.

Rubio Correa, P. (1999). El concepto de refugiado en la Convención sobre el Estatuto de los refugiados de 1951: tratamiento normativo y realidad. Agenda Internacional, 6 (12) 137148.

Sánchez de Bustamante y Sirven, A. (1938). Derecho Internacional Público. La Habana: Carasa y CIA S.A.

Tratado sobre Asilo y Refugio Político de Montevideo (1939).

Vilariño Pintos, E. (2016). Curso de Derecho Diplomático y Consular. Madrid: Tecnos. S.A. 